\title{
Compliance at night with low flow oxygen therapy: a comparison of nasal cannulae and Venturi face masks
}

\author{
Richard W Costello, Richard Liston, Walter T McNicholas
}

\begin{abstract}
Background - The factors that influence nocturnal compliance among patients prescribed low flow oxygen therapy were determined and tolerance of nasal cannulae and Venturi face masks compared.

Methods - Two studies were performed: (1) a prospective study of 99 hospitalised patients prescribed low flow oxygen therapy, 49 on nasal cannulae and 50 on Venturi face mask; and (2) a prospective study of 20 separate patients with an acute respiratory disorder requiring low flow oxygen therapy who were given nasal cannulae and Venturi face mask on successive nights in random order.

Results - In study 1, 49 patients dislodged their device at least once during the night. Those using Venturi face masks and those over 75 years of age had the most dislodgements. In study 2 patients also dislodged Venturi face masks more frequently (mean (SD) $2 \cdot 0(2 \cdot 4)$ ) than nasal cannulae $(0.7(1 \cdot 4))$. Most patients expressed a preference for nasal cannulae.

Conclusions - Nocturnal tolerance of nasal cannulae is superior to Venturi face masks, and this factor should be considered when choosing the method of oxygen delivery.

(Thorax 1995;50:405-406)
\end{abstract}

Keywords: Venturi mask, nasal cannulae, nocturnal hypoxaemia.

The most common methods of low flow oxygen therapy are nasal cannulae and Venturi masks. Venturi masks give better control of the inspired oxygen concentration $\left(\mathrm{FIO}_{2}\right)$ than nasal cannulae, ${ }^{1-3}$ but are less comfortable and may become dislodged during sleep, which has particular relevance because of sleep-related hypoxaemia. ${ }^{45}$

There have been no detailed studies comparing tolerance of nocturnal oxygen therapy by nasal cannulae and Venturi face masks, although nasal cannulae have been shown to stay in place

Table 1 Diagnostic categories

\begin{tabular}{lrrr}
\hline & \multicolumn{2}{l}{ Study 1} & $\begin{array}{l}\text { Study } 2 \\
\text { VM and NC }\end{array}$ \\
\cline { 2 - 3 } & $V M$ & $N C$ & \\
\hline COPD & 15 & 15 & 13 \\
Pneumonia & 14 & 1 & $5(1$ died $)$ \\
Lung fibrosis & 0 & 0 & 2 \\
LVF & 6 & 15 & 0 \\
Postoperative & 6 & 8 & 0 \\
Miscellaneous & 9 & 10 & 0 \\
\hline
\end{tabular}

$\mathrm{NC}=$ nasal cannulae; $\mathrm{VM}=$ Venturi face mask $\mathrm{LVF}=$ left vent ricular failure; $\mathrm{COPD}=$ chronic obstructive lung disease. better than Venturi face masks among postoperative patients. ${ }^{6}$

\section{Methods}

STUDY 1

Ninety nine hospitalised non-ICU patients on low flow oxygen therapy were studied prospectively (table 1). The oxygen concentration and choice of device was decided by the attending clinician, based on the individual patient's requirement and independent of the investigators. The device was either nasal cannulae (Intersurgical Ltd, Wokingham, Berkshire, UK) or a Venturi face mask (Intersurgical Ltd), and flow rates were 2 litres/min for nasal cannulae and $24 \%$ or $28 \%$ by Venturi face mask.

The presence of confusion was assessed by a 10 point mental status questionnaire ${ }^{7}$ and awake arterial blood gas tensions were measured on room air. In patients prescribed nasal cannulae, a record was made of whether the device was looped around the ears or tied behind the head. At half-hourly intervals between midnight and 08.00 hours the ward nursing staff, who were blinded to the purpose of the study, checked the position of the device, replacing it if necessary, and recorded sleep status.

\section{STUDY 2}

A separate group of 20 hypoxaemic patients was studied in a randomised prospective crossover fashion comparing the same two devices. Patients were emergency admissions to our unit requiring low concentration oxygen therapy, excluding those on long term home oxygen (LTOT), and most had an exacerbation of chronic obstructive pulmonary disease (COPD) (table 1). Patients were prescribed nasal cannulae and Venturi face masks on successive nights in random order, and arterial blood gas measurements were repeated to ensure adequate supplementation. The data collection on each night was identical to that in study 1 .

\section{STATISTICAL ANALYSIS}

Statistical analysis was by the Student's $t$ test, Mann-Whitney U test, $\chi^{2}$ analysis, or Wilcoxon matched pairs test as appropriate.

\section{Results}

STUDY 1

Among the 99 patients 49 were prescribed nasal cannulae and 50 Venturi face masks, the 
Table 2 Mean (SD) clinical details and oxygen compliance

\begin{tabular}{|c|c|c|c|c|c|c|}
\hline & \multicolumn{5}{|l|}{ Study 1} & \multirow[t]{2}{*}{ Study 2} \\
\hline & Total & $V M$ & $N C$ & $\begin{array}{l}\text { Zero } \\
\text { dislodgements }\end{array}$ & $\begin{array}{l}\text { One or more } \\
\text { dislodgements }\end{array}$ & \\
\hline Number & 99 & 49 & 50 & 50 & 49 & 20 \\
\hline Age (years) & $73(13)$ & $75(14)$ & $71(11)$ & $71(13)^{*}$ & $76(12)^{*}$ & $70(13)$ \\
\hline $\mathrm{PaO}_{2}(\mathrm{RA}, \mathrm{kPa})$ & $8 \cdot 3(2 \cdot 1)$ & $8 \cdot 2(2 \cdot 3)$ & $8 \cdot 4(2 \cdot 1)$ & $8 \cdot 1(2 \cdot 0)$ & $8 \cdot 4(2 \cdot 1)$ & $7 \cdot 9(1 \cdot 3)$ \\
\hline $\mathrm{PaCO}_{2}(\mathrm{RA}, \mathrm{kPa})$ & $5 \cdot 4(1 \cdot 1)$ & $5 \cdot 1(1 \cdot 0)$ & $5 \cdot 6(1 \cdot 1)$ & $5 \cdot 4(1 \cdot 1)$ & $5 \cdot 2(1 \cdot 1)$ & $5 \cdot 7(1 \cdot 1)$ \\
\hline Percent hypercapnic $(>6.1 \mathrm{kPa})$ & 24 & 9 & 15 & 14 & 10 & 35 \\
\hline Slept well $(\%)$ & 57 & 53 & 58 & $81^{* *}$ & $52 * *$ & \\
\hline LTOT & 4 & 0 & 4 & 4 & 0 & 0 \\
\hline Confusion & 17 & $12^{*}$ & $5^{*}$ & 6 & 11 & 2 \\
\hline Dislodgements & & $2 \cdot 3(2 \cdot 9)^{* *}$ & $0 \cdot 8(1 \cdot 3)^{* *}$ & & & \\
\hline $\begin{array}{l}\text { Dislodgements (excl LTOT and } \\
\text { confusion) }\end{array}$ & & $1.6(1.9)^{*}$ & $0 \cdot 8(1 \cdot 3)^{*}$ & & & \\
\hline NC dislodgements & & & & $64 \% * *$ & $37 \% * *$ & $0.7(1.4) \dagger$ \\
\hline VM dislodgements & & & & $39 \% *$ & $63 \% *$ & $2 \cdot 0(2 \cdot 4) \dagger$ \\
\hline
\end{tabular}

$\mathrm{RA}, \mathrm{kPa}=$ room air in kilopascals; LTOT $=$ long term oxygen therapy; $\mathrm{NC}=$ nasal cannulae; $\mathrm{VM}=$ Venturi mask.

${ }^{*} \mathrm{p}<0 \cdot 05 ;{ }^{* *} \mathrm{p}<0 \cdot 01$ for differences between variables.

$t \mathrm{p}<0.05$ for comparison of nasal cannulae and Venturi face mask dislodgements in study 2 .

almost equal divide being fortuitous. More patients in the Venturi face mask group were confused (table $2 ; \mathrm{p}<0.05$ ) and all four on LTOT were in the nasal cannulae group. Venturi masks were dislodged much more frequently than nasal cannulae $(p<0.005)$ (figure). Furthermore, when patients on LTOT and confused patients were excluded, differences between the two groups remained significant $(\mathrm{p}<0 \cdot 05)$. Table 2 also shows that use of nasal cannulae, young age, and good sleep were factors significantly associated with no dislodgements. Compliance with nasal cannulae was similar with the device looped around the ears or tied behind the head.

Stratified multivariate analysis showed both types of device and age to be significant independent factors influencing nocturnal oxygen tolerance when adjusted for other factors such as, sex, confusion, and sleep quality (relative risk 0.57 , confidence interval 0.43 to $0.94, p<0.05$ for device used; and $0.4,0.21$ to $0.91, \mathrm{p}=0.05$ for age).

STUDY 2

All 20 patients completed the nasal cannulae part of the study, but only 17 completed the Venturi face mask part (one died after the first night and two refused to use the Venturi face mask because of discomfort). Again, Venturi face masks required more replacement than nasal cannulae among the 17 patients who wore both devices ( $p<0 \cdot 05$, table 2$)$. Only six of 17 patients who wore Venturi face masks overnight had zero dislodgements, compared with 14 of 20 with nasal cannulae ( $\mathrm{p}<0.05, \chi^{2}$ analysis, Yates corrected). Seventeen of the 19 patients who experienced both devices preferred nasal cannulae.

\section{Discussion}

Our findings have clinical significance because of the potential for nocturnal hypoxaemia in

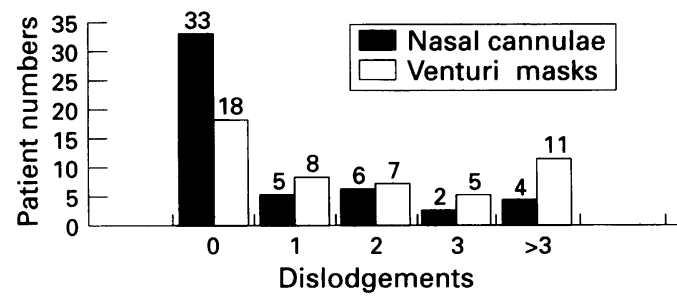

Number of dislodgements in study 1.
$\mathrm{COPD}^{12}$ and because hypoxaemic patients $\overrightarrow{\vec{\omega}}$ with COPD are prone to die at night. ${ }^{8}$ However, nasal cannulae are restricted to patients without $x$ nasal obstruction and $\mathrm{FIO}_{2}$ is less accurately controlled than with the Venturi face mask. This advantage of the Venturi face mask is lost of if the device becomes dislodged, although close $\circ$ nursing supervision during the early stages of an acute exacerbation of COPD should improve compliance. While Venturi face masks have a greater range of flow rates than nasal cannulae, $\vec{\theta}$ they are bulky and uncomfortable. Our data 6 do not establish the comparative efficacy of each device in maintaining adequate gas exchange during sleep since we did not monitor oxygen saturation during sleep.

The data indicate that compliance is an im- $\frac{\varnothing}{\varnothing}$ portant consideration when choosing the route of nocturnal oxygen therapy. Thus, the relative 0 importance of accurate control of $\mathrm{FIO}_{2}$ and compliance must be determined when selecting the route of oxygen delivery for each patient. Our data indicate that some may be better managed with nasal cannulae, particularly $\underset{x}{\stackrel{0}{N}}$ normocapnic patients who do not require high flow oxygen therapy, and elderly patients.

Patients with hypercapnic respiratory failure $\delta$ benefit from the more accurate control of $\mathrm{FIO}_{2}$ provided by Venturi face masks, but care must 윽 be taken to ensure adequate compliance since the abrupt withdrawal of oxygen supplementation may result in more severe $\tilde{N}$ hypoxaemia than before supplementation. Patients in this category who tolerate Venturi face masks poorly may therefore be better man- $\mathrm{C}$ aged by nasal cannulae.

1 Green ID. Choice of method for administration of oxygen. BMF 1967;3:593-6.

2 Ooi R, Joshi P, Soni N. An evaluation of oxygen delivery using nasal prongs. Anaesthesia 1992;47:591-3.

3 Bazuaye EA, Stone TN, Corris PA, Gibson GJ. Variability of inspired oxygen concentration with nasal cannulae. Thorax

4 Douglas NJ, Calverley PMA, Leggett RJE, Brash HM, Flenley DC, Brezinova V. Transient hypoxaemia during sleep in chronic bronchitis and emphysema. Lancet 1979;i:1-4

5 Goldstein RS, Ramcharan V, Bowes G, McNicholas WT, Bradley D, Phillipson EA. Effects of supplemental nocturnal oxygen on gas exchange in patients with severe obstructive lung disease. $N$ Engl f Med 1984;310:425-9.

6 Nolan KM, Winyard JA, Goldhill DR. Comparison of nasal cannulae with face mask for oxygen administration to postoperative patients. $\mathrm{Br} \mathcal{F}$ Anaesth 1993;70:440-2.

7 La Rue A, D'Elia LF, Clark EO, Spar JE, Jarvik LF. Clinical tests of memory in dementia, depression and healthy aging. Psychol Aging 1986;1:69-77.

8 McNicholas WT, FitzGerald MX. Nocturnal deaths among patients with chronic bronchitis and emphysema. $B M \mathcal{F}$ 1984;289:878. 